\title{
DESENVOLVIMENTO DE SOFTWARE E HARDWARE PARA IRRIGAÇÃO DE PRECISÃO USANDO PIVÔ CENTRAL ${ }^{1}$
}

\section{TADEU M. DE QUEIROZ ${ }^{2}$, TARLEI A. BOTREL ${ }^{3}$, JOSÉ A. FRIZZONE ${ }^{4}$}

\begin{abstract}
RESUMO: O presente trabalho teve por objetivo desenvolver softwares e hardwares para aplicação ao monitoramento e controle automático para a irrigação de precisão usando sistemas do tipo pivô central. O trabalho foi desenvolvido no Departamento de Engenharia Rural - LER, da Escola Superior de Agricultura "Luiz de Queiroz" - ESALQ, da Universidade de São Paulo - USP, em Piracicaba - SP. Foram utilizados componentes eletrônicos discretos, circuitos integrados diversos, módulos de radiofreqüência, microcontroladores da família Basic Step e um microcomputador. Foram utilizadas as linguagens Delphi e TBasic. O hardware é constituído de dois circuitos eletrônicos, sendo um deles para "interface" com o computador e o outro para monitoramento e transmissão da leitura de tensiômetros para o computador via radiofreqüência. Foram feitas avaliações do alcance e da eficiência na transmissão de dados dos módulos de radiofreqüência e do desempenho do software e do hardware. Os resultados mostraram que tanto os circuitos quanto os aplicativos desenvolvidos apresentaram funcionamento satisfatório. Os testes de comunicação dos rádios indicaram que esses possuem alcance máximo de $50 \mathrm{~m}$. Concluiu-se que o sistema desenvolvido tem grande potencial para utilização em sistemas de irrigação de precisão usando pivô central, bastando para isso que o alcance dos rádios seja aumentado.
\end{abstract}

PALAVRAS-CHAVE: automação, eletrônica, manejo da irrigação.

\section{DEVELOPMENT OF SOFTWARE AND HARDWARE FOR PRECISION IRRIGATION USING THE CENTER PIVOT}

\begin{abstract}
The objective of this work was to develop softwares and hardwares applied to the management and automatic control for precision irrigation using center pivot systems. They were developed in the Rural Engineering Department - LER, at the "Luiz de Queiroz" College of Agriculture - ESALQ, of São Paulo University - USP, in Piracicaba, SP-Brazil. It was used discrete electronic components, several integrated circuits, radio frequency modules, microcontrollers from the Basic Step family and a microcomputer. The computer software was developed in Delphi language, and the Basic Step software was developed in Tbasic language. The hardware was constituted by two electronic circuits. The first circuit was developed as an interface to the computer and the second one for the management and transmission of tensiometers readings through radio frequency Evaluations of range and efficiency of the radio modules and performance of data transmission, of the software and hardware operations were carried out. The results showed that the circuits and the developed software operated satisfactorily. The reliable communication range of the radios is 50 meters maximum. In conclusion, the developed system presented great potential used in precision irrigation for center pivot systems, since the range of the radio communication could be increased.
\end{abstract}

KEYWORDS: automation, electronic, irrigation management.

\footnotetext{
${ }^{1}$ Extraído da tese de Doutorado do primeiro autor. Projeto financiado pelo CNPq.

${ }^{2}$ Eng ${ }^{0}$ Agrícola, Docente do Departamento de Engenharia da Produção Agroindustrial, UNEMAT - Barra do Bugres - MT, Fone: (0XX65) 3361.3752, tadeubbg@unemat.br

${ }^{3}$ Eng $^{\mathrm{O}}$ Agrícola, Prof. Doutor, Departamento de Engenharia Rural, ESALQ/USP - Piracicaba - SP.

${ }^{4}$ Eng ${ }^{0}$ Agrônomo, Prof. Doutor, Departamento de Engenharia Rural, ESALQ/USP - Piracicaba - SP.

Recebido pelo Conselho Editorial em: 10-1-2007
}

Aprovado pelo Conselho Editorial em: 18-1-2008 


\section{INTRODUÇÃO}

O Brasil vive um momento histórico que parece ser o marco inicial da "Revolução Hídrica" nacional, onde começa a se exigir outorga para uso da água e até mesmo o pagamento pela vazão recalcada. O que já não é mais novidade, pois, nos países ditos "desenvolvidos", esse processo já ocorre com naturalidade.

A irrigação é uma técnica de produção agrícola que concorre, em algumas regiões, diretamente com a indústria e as cidades, pelo uso da água, sendo vista nesse processo como vilã, pois o volume de água utilizado é demasiadamente grande. Todavia, essa é uma ação necessária, pois a aplicação de água nas culturas aumenta a eficiência de uso de outros insumos, como fertilizantes, por exemplo, garante a produção na entressafra em regiões áridas ou de regime pluviométrico inconstante, além de oferecer segurança durante os veranicos.

O maior desafio deste século para a Engenharia Agrícola, na cadeia da irrigação, será o desenvolvimento de métodos e sistemas mais eficientes na aplicação e no uso da água. Nesse contexto, a eletrônica como ferramenta para automação desempenha papel fundamental.

O pivô central é, segundo VILELA (2002), o sistema de irrigação por aspersão mais automatizado que existe no mercado, podendo essa automação variar desde um simples acessório a controladores que permitem o seu acionamento a distância por meio de ondas de rádio ou telefone celular. No entanto, esse é um tipo de automação que tem a finalidade apenas de economizar tempo e mão-de-obra, já que o sistema opera em malha aberta. A automação desejada e implementada deve ser aquela que considera a informação de sensores no solo, na planta ou na atmosfera, para o acionamento do sistema de irrigação e não um calendário programável.

Para o monitoramento da variação do conteúdo de água no solo, o tensiômetro é um dos instrumentos mais utilizados e recomendados (SAAD \& LIBARDI, 1994; ANGELOTTI NETO \& FERNANDES, 2005; BERNARDO et al., 2006). A utilização desse instrumento para a automação da irrigação no Brasil teve início com o trabalho de MÉDICI (1997) e desenvolvimentos futuros feitos por QUEIROZ et al. (2002) e QUEIROZ (2004) empregando sistemas analógicos. Entretanto, com o surgimento no mercado brasileiro de transdutores de pressão de baixo custo e de fácil aplicação, a diversidade de microcontroladores e de linguagens de programação, sistemas mais sofisticados estão sendo desenvolvidos, a exemplo do trabalho de TEIXEIRA \& COELHO (2005), que utilizaram transdutores de pressão e temperatura em um sistema automático de aquisição de dados, com o objetivo de avaliar o efeito da temperatura na leitura de tensiômetros.

Em sistemas de irrigação como o pivô central, que se aplica a grandes áreas, a comunicação de sensores com um controlador via cabos é inviável por causa da grande distância. Portanto, a utilização de sistemas de transmissão de dados via radiofreqüência mostra-se como uma ferramenta cada vez mais atraente e aplicável e, com isso, a exemplo da mecanização, a irrigação poderá ser de precisão. Nesse contexto, o presente trabalho teve por objetivo desenvolver softwares e hardwares dedicados ao monitoramento e ao controle automático para a irrigação de precisão em sistemas do tipo pivô central.

\section{MATERIAL E MÉTODOS}

Para o desenvolvimento do aplicativo computacional, partiu-se do princípio de que é possível fazer uma irrigação de precisão dividindo a área do pivô em setores (fatias), conforme o esquema utilizado em pastejo irrigado descrito por XAVIER et al. (2004). Desse modo, cada setor pode conter um conjunto de tensiômetros, e a lâmina aplicada pode ser calculada individualmente com base nas leituras desses. Para tanto, foi projetado um sistema capaz de obter a leitura dos tensiômetros utilizando uma interface wireless, que foi implementada por meio de módulos de radiofreqüência. O sistema desenvolvido foi denominado PivoRF e opera em duas versões: usuário e administrador. 
O aplicativo PivoRFusuario proposto identifica a posição da torre do pivô e aciona, por meio de um sistema de controle remoto via radiofreqüência, o circuito de monitoramento do conjunto de tensiômetros do setor subseqüente. Com base na leitura dos tensiômetros, o aplicativo calcula a lâmina requerida e ajusta automaticamente o percentímetro para aquele setor. Em seguida, o aplicativo envia um sinal para desligar o circuito de monitoramento, grava os dados lidos e calculados em um arquivo no formato "XLS" e retorna para a rotina que lê a posição. Quando a torre do pivô atinge uma nova posição, o processo repete-se até que toda a área seja irrigada.

O sistema pode ser utilizado considerando o perfil do solo homogêneo ou heterogêneo. Quando for homogêneo, pode-se utilizar uma única curva de retenção para todas as camadas de solo de interesse e que contenham tensiômetros instalados; nesse caso, a espessura das camadas também deve ser idêntica. No caso de haver um solo com camadas de características diferentes, pode-se ter uma curva de retenção para cada camada, e essa poderá ter espessura diferente. Toda vez que o PivôRFusuario inicia uma nova aplicação, abre-se um arquivo de texto e consideram-se as informações nele contidas para os cálculos da lâmina requerida e do valor do percentímetro.

A lâmina de irrigação requerida é calculada de acordo com o tipo de solo. No caso em que o solo for heterogêneo ao longo do perfil, utiliza-se da eq.(1):

$$
\mathrm{hr}=\frac{\sum_{\mathrm{i}=1}^{\mathrm{n}}\left(\theta_{\mathrm{CCi}}-\theta_{\mathrm{i}}\right) \mathrm{z}_{\mathrm{i}}}{10}
$$

em que,

hr - lâmina de irrigação requerida, mm;

$\theta_{\mathrm{CCi}}$ - umidade na capacidade de campo (base volume), da iésima camada, \%;

$\theta_{\mathrm{i}}$ - umidade atual (base volume) da iésima camada, \%, e

$\mathrm{z}_{\mathrm{i}}$ - espessura da iésima camada, $\mathrm{cm}$.

Quando o perfil do solo for homogêneo, a eq. (1) é simplificada [eq.(2)].

$$
\mathrm{hr}=\frac{\sum_{\mathrm{i}=1}^{\mathrm{n}}\left(\theta_{\mathrm{CC}}-\theta_{\mathrm{i}}\right) \mathrm{z}}{10}
$$

em que,

$\theta c c$ - umidade na capacidade de campo (base volume), em todas as camadas, $\%$, e

$\mathrm{Z}$ - espessura das camadas, $\mathrm{cm}$.

Com base na lâmina requerida, calculada pelas eqs.(1) ou (2), e na lâmina média mínima aplicada pelo pivô, calcula-se o valor do percentímetro pela eq.(3):

$$
\text { Perc }=\operatorname{Trunc}\left(\frac{\mathrm{h}_{\min }}{\mathrm{hr}} 100\right)
$$

em que,

Perc - valor do percentímetro, \%;

Trunc - função matemática que arredonda um número para o valor inteiro inferior, e

$\mathrm{h}_{\text {min }}$ - lâmina média mínima aplicada pelo pivô, $\mathrm{mm}$.

Com base no valor do percentímetro, calcula-se, pelas eqs. (4) e (5), o tempo em que a última torre do pivô deve ficar ligada e desligada, respectivamente.

$$
\mathrm{TL}=\frac{60 \text { Perc }}{100}
$$

em que,

TL - tempo em que a última torre deve ficar ligada, segundos. 


$$
\mathrm{TD}=60 \frac{(100-\text { Perc })}{100}
$$

em que,

TD - tempo em que a última torre deve ficar desligada, segundos.

O valor do percentímetro, calculado na eq.(3), foi truncado (TRUNC) a fim de permitir a comunicação com o microcontrolador Basic Step, pois esse não reconhece números fracionados. Os valores TL e TD juntos devem somar 60 segundos. Na programação, foi considerada uma restrição para o caso de a lâmina requerida $(\mathrm{hr})$ ser menor do que a lâmina média mínima $\left(\mathrm{h}_{\mathrm{min}}\right)$. Nesse caso, converte-se automaticamente o valor da lâmina requerida para 'zero', e o valor do percentímetro para $100 \%$, e desliga-se o sistema de adução, fazendo o pivô deslocar-se na velocidade máxima sem aplicar água.

O aplicativo PivoRFadministrador é utilizado para criar um arquivo de dados referentes à curva de retenção, à espessura das camadas, ao número de camadas por setor, ao número de setores e aos dados técnicos do pivô e dos tensiômetros. Esse arquivo é utilizado pelo PivoRFusuario.

Na Figura 1, são mostrados os fluxogramas gerais dos aplicativos PivoRFusuario (a) e PivoRFadministrador (b).

(a)

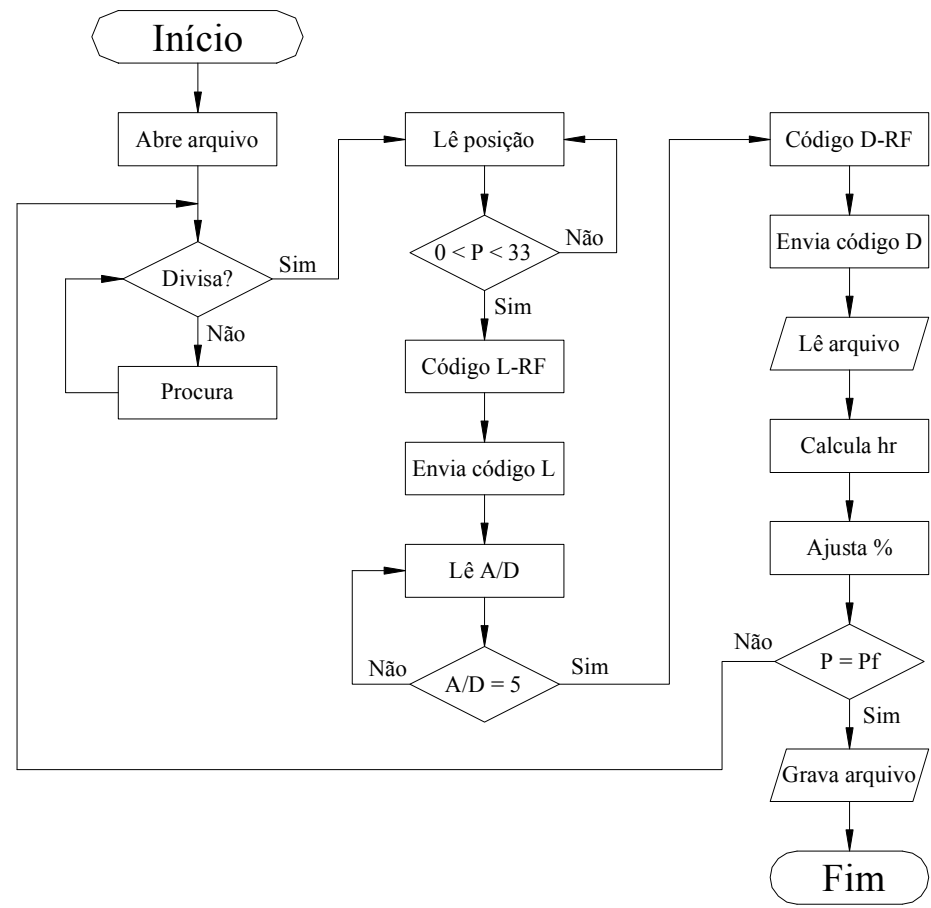

(b)

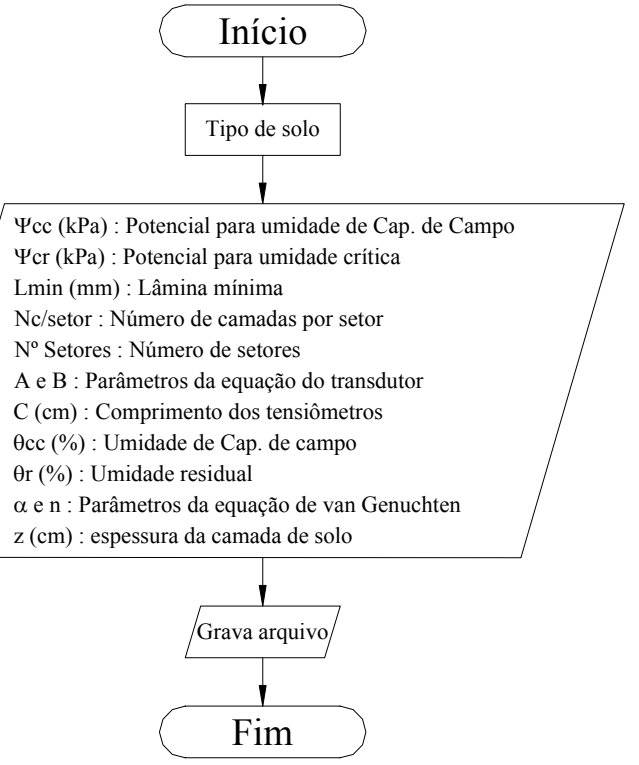

FIGURA 1. Fluxograma do aplicativo PivoRFusuario (a) e PivoRFadministrador (b). Flowchart of PivoRFusuario applicative (a) and PivoRFadministrador (b).

Foram utilizados, neste projeto, três microcontroladores, sendo um para a identificação da posição do pivô e envio da mesma para o computador, outro para receber o valor do percentímetro e controlar a velocidade da última torre do pivô, e o último para fazer o monitoramento dos tensiômetros e enviar os valores lidos nos 5 canais do A/D, para o computador, via radiofreqüência. Na Figura 2, são mostrados os fluxogramas desses aplicativos.

O circuito de monitoramento foi construído utilizando-se de microcontrolador Basic Step modelo OEM, o qual possui conversor Analógico/Digital (A/D) de 10 "bits" e 5 canais. O mesmo possui instrução para transmissão de dados seriais à taxa de 2.400 "bits" por segundo (bps). A cada canal do A/D pode ser ligado um tensiômetro, oferecendo-se, assim, a opção de trabalhar com até cinco camadas de solo diferentes. Para a transmissão dos valores lidos nos cinco canais do A/D, foi utilizado um Transmissor de RF de 433,9 MHz, com alcance de 50 a $100 \mathrm{~m}$, segundo o fabricante. 
Esse circuito permanece desligado e é acionado por um circuito auxiliar que recebe sinal de controle remoto originado no computador, sendo acionado apenas o circuito da fatia de interesse, de acordo com a posição da torre do pivô. Na Figura 3(a), é mostrado o diagrama desse circuito, e, na Figura 3(b), é mostrado o circuito auxiliar.

(a)

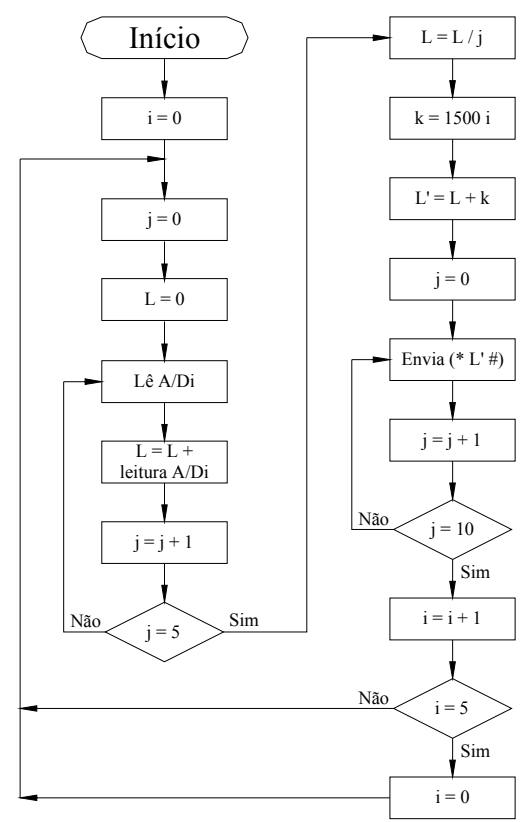

(b)

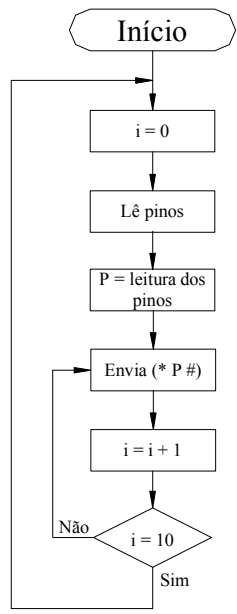

(c)

FIGURA 2. Fluxogramas dos aplicativos, monitoramento de tensiômetros (a), identificação da posição do pivô (b) e controle da velocidade da última torre (c). Flowcharts of applications, tracking tensiometers (a) identification of the position of the pivot (b) and control the speed of the last tower (c).

(a)

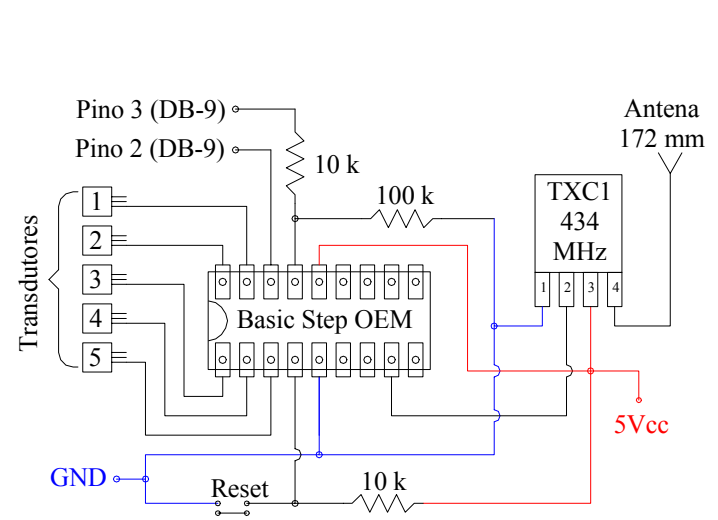

(b)

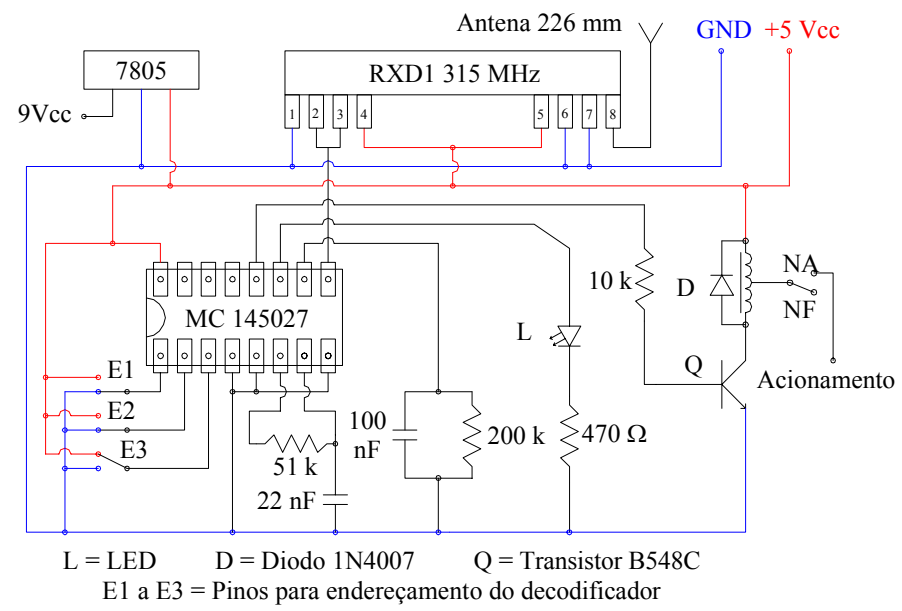

FIGURA 3. Diagrama do circuito de monitoramento dos tensiômetros e transmissão de dados via radiofreqüência (a) e do receptor do sinal de acionamento remoto via RF (b). Diagram of the tracking circuit of tensiometers and transmitting data via radio frequency (a) and the receiver of the signal via RF Remote Trigger (b). 


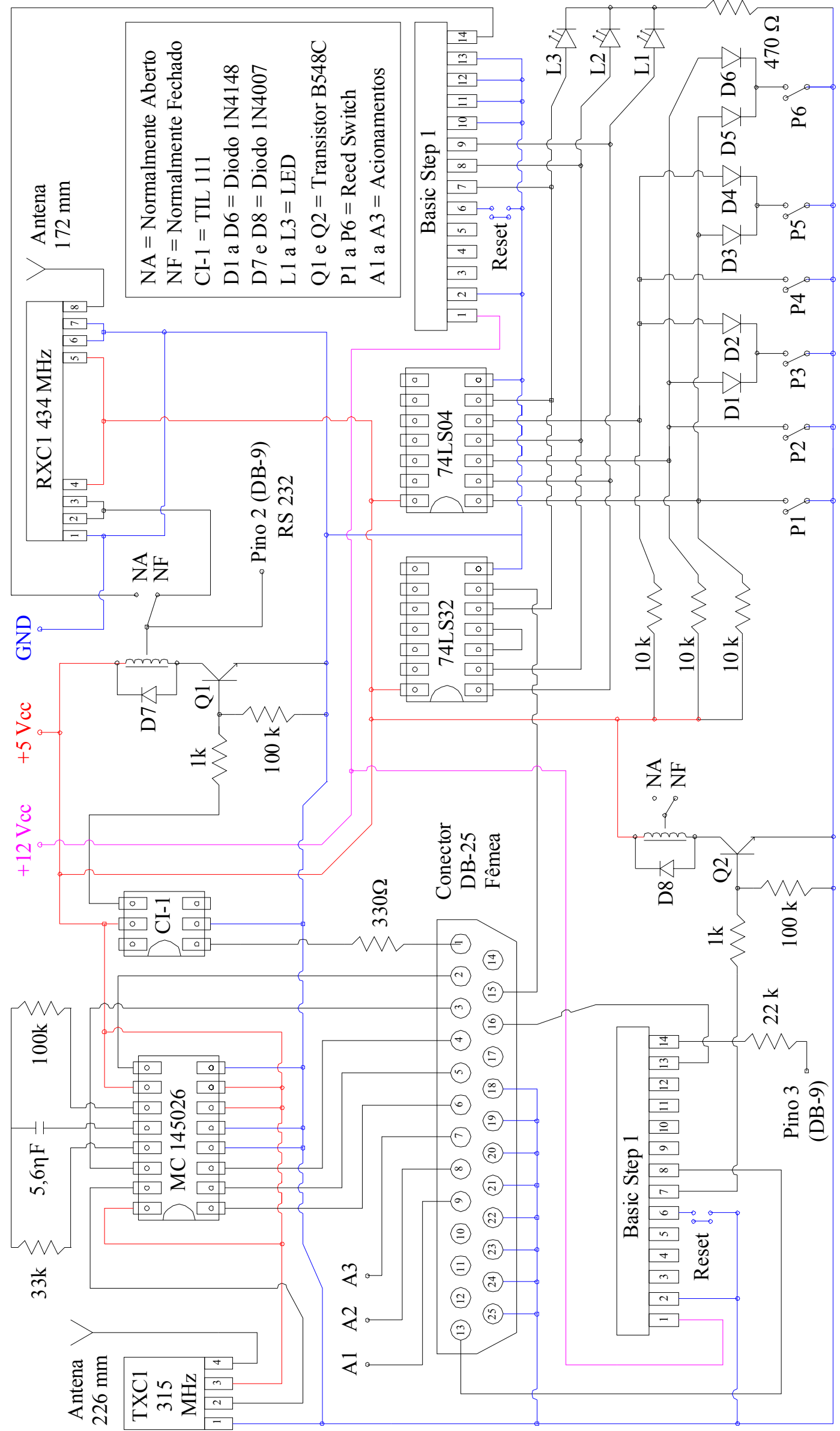

FIGURA 4. Diagrama do circuito de "interface" com o computador. Diagram of the circuit of interface with the computer. 
O circuito auxiliar de acionamento foi construído utilizando-se de um receptor de RF de $315 \mathrm{MHz}$ e um circuito integrado (CI) decodificador ("decoder" MC 145027). Foram escolhidas as freqüências de $315 \mathrm{MHz}$ e 433,9 MHz para o circuito auxiliar de acionamento e o circuito de monitoramento e de transmissão de dados, respectivamente, para evitar conflito nos sinais dos mesmos. O CI decodificador possui cinco entradas para codificação, o que dá até $32\left(2^{5}=32\right)$ endereços diferentes. Neste projeto, foram utilizadas apenas três entradas (E1, E2 e E3), permitindo a criação de até $8\left(2^{3}=8\right)$ endereços. Os circuitos mostrados das Figuras 3(a) e 3(b), depois de testados em matriz de contato, foram impressos em placa própria (fenolite cobreada), a fim de facilitar o manuseio, sendo os mesmos isolados em caixas plásticas hermeticamente fechadas, e utilizaram seis pilhas pequenas para a sua alimentação. Foram construídas seis unidades desse circuito a fim de realizar a simulação de controle da irrigação em seis setores diferentes.

O circuito de "interface" com o computador tem quatro funções básicas: identificar a posição da torre do pivô, controlar o circuito auxiliar de acionamento, receber os sinais dos tensiômetros e controlar automaticamente o percentímetro do pivô. O seu diagrama é mostrado na Figura 4.

Tanto para a identificação da posição do pivô, quanto para o controle do percentímetro, foram utilizados microcontroladores Basic Step do modelo BS1. No circuito de controle remoto, foram utilizados um transmissor de RF (315 MHz) e um codificador ("encoder" MC 145026) controlado pela porta paralela do computador, o qual foi montado conforme MESSIAS (2005). O circuito de recepção dos sinais dos tensiômetros é simplesmente um receptor de RF de 433,9 MHz.

\section{RESULTADOS E DISCUSSÃO}

Na Figura 5, são mostradas as telas inicial e principal do aplicativo PivoRFusuario.

(a)

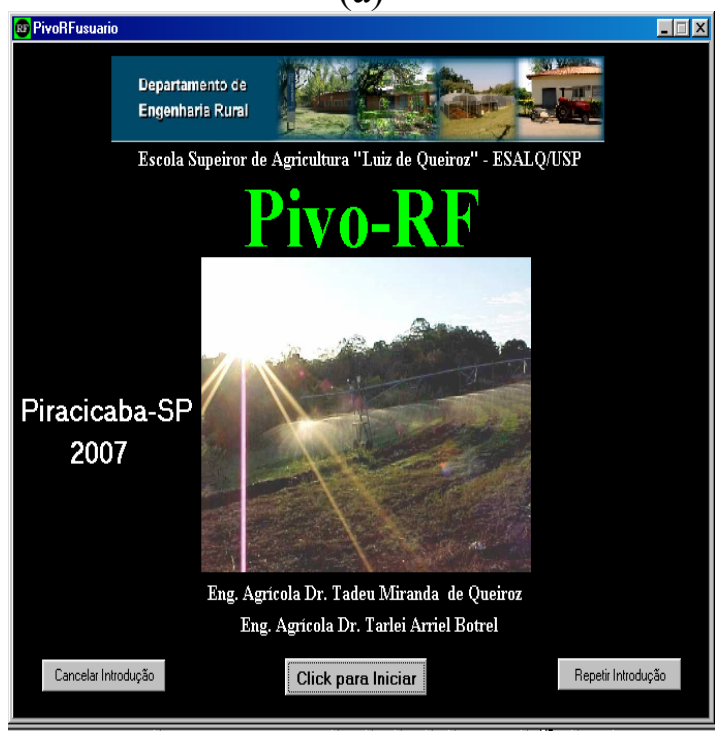

(b)

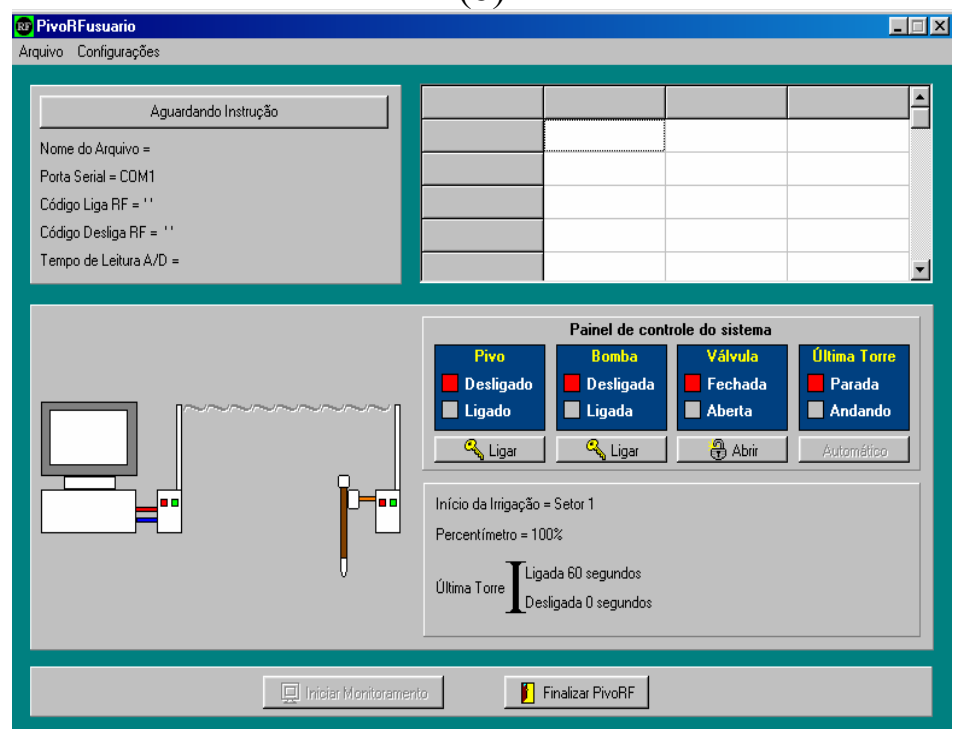

FIGURA 5. Tela inicial (a) e tela principal (b) do aplicativo PivoRFusuario. Initial screen (a) and main screen (b) of the PivoRFusuario applicative.

Os aplicativos foram desenvolvidos para permitir o mínimo de interação com o usuário, a fim de evitar erros de configuração, visto que a transmissão via radiofreqüência emprega parâmetros muito específicos, como, por exemplo, a taxa de transmissão de dados. A tela principal apresenta dois menus. No menu "arquivo", o usuário tem a opção de abrir um arquivo, começar o monitoramento e sair do programa. Já no menu "configurações", o usuário tem a opção de escolher o tipo de solo e qual porta serial será utilizada. O aplicativo adota a porta "COM1" como padrão, porque essa é a porta que está disponível na maioria dos computadores. Entretanto, se no computador utilizado a porta serial disponível não for a "COM1", o usuário poderá habilitar a que 
estiver disponível, escolhendo entre "COM2", "COM3" ou "COM4". Nessa tela, também existem dois botões de ação: um para iniciar o programa e outro para finalizar a aplicação.

Na Figura 6, é mostrada a tela principal do aplicativo PivoRFadministrador. Essa tela também tem dois menus, sendo o menu "arquivo" com as opções: "abrir", "salvar", "novo" e "sair". Como o próprio nome sugere, o submenu 'abrir' abre um arquivo por meio da caixa de diálogo; o 'salvar' salva os dados digitados na tela no formato TXT, o 'novo' limpa a tabela para a entrada de um novo conjunto de dados, e o 'sair' finaliza o aplicativo.

No painel, abaixo da tabela, estão as caixas para a entrada de dados referentes ao solo, pivô, transdutor e tensiômetro. Os dados são: potencial para umidade na capacidade de campo, em $\mathrm{kPa}$ ( $\Psi \mathrm{cc})$, potencial para umidade crítica, em kPa ( $\Psi \mathrm{cr})$, lâmina mínima aplicada pelo pivô, em mm $\left(\mathrm{L}_{\min }\right)$, número de camadas por setor $(\mathrm{Nc} / \mathrm{setor})$, número de setores de irrigação $\left(\mathrm{n}^{\mathrm{o}}\right.$ setores), coeficiente angular da equação de calibração dos transdutores (A), coeficiente linear da mesma equação (B) e comprimento dos tensiômetros, em cm (T1, T2, T3, T4 e T5).

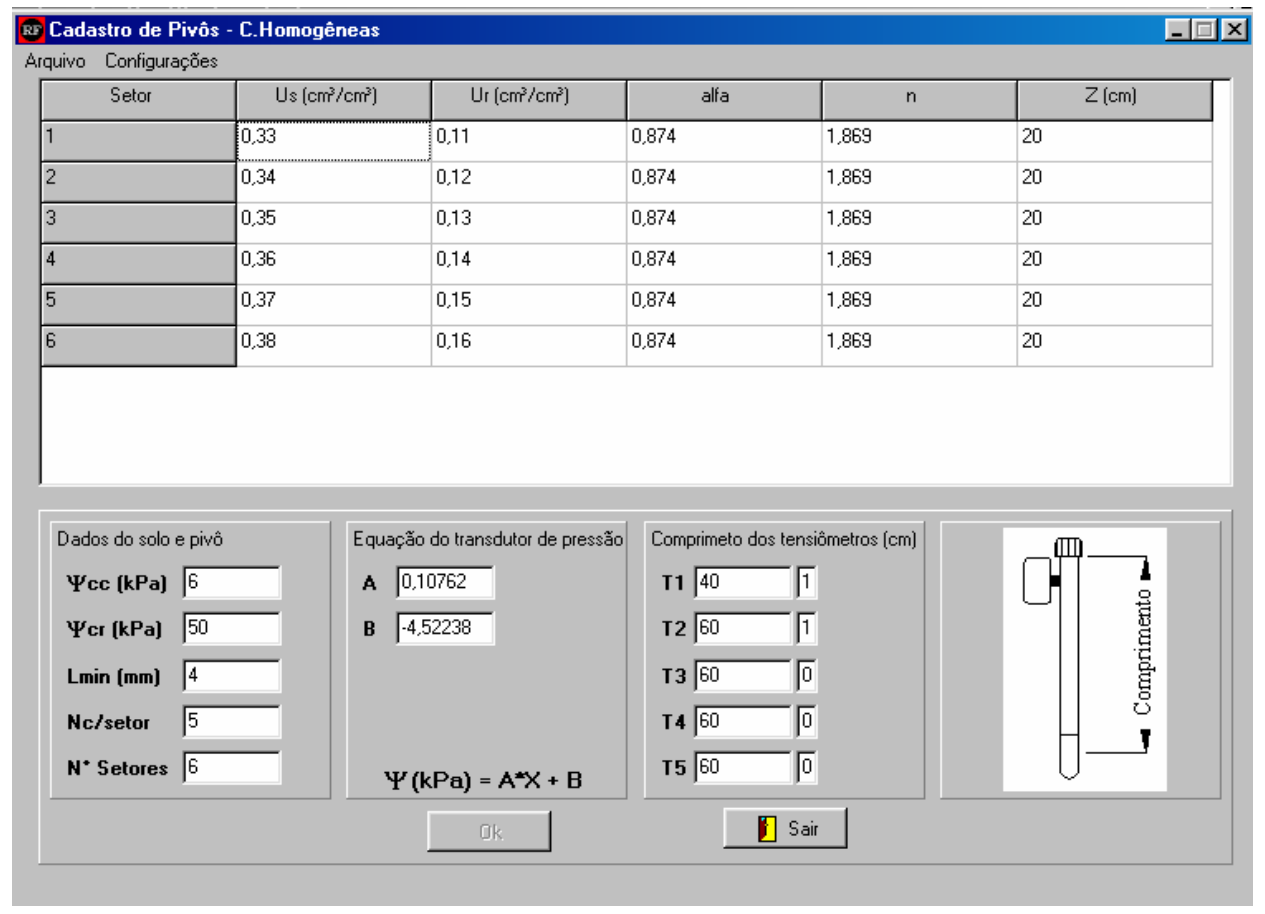

FIGURA 6. Tela principal do aplicativo PivoRFadministrador. Main screen of the PivoRFadministrador applicative.

Tanto o software quando o hardware desenvolvidos oferecem a possibilidade de utilizar até cinco tensiômetros por setor. No caso de trabalhar com um número menor, devem-se desabilitar os canais que não forem utilizados, bastando para isso preencher a coluna ao lado do comprimento dos tensiômetros com valores de ' 1 ' (considerar) e ' 0 ' (desconsiderar).

$\mathrm{Na}$ Figura 7, é mostrada uma tela do Excel $^{\circledR}$ contendo arquivo de dados gerados pelo aplicativo PivoRFusuario. Nessa simulação, foi considerado um solo heterogêneo, ou seja, com camadas de características diferentes.

Nessa Figura, observa-se que o aplicativo salva no arquivo o número do setor irrigado, a hora da leitura dos tensiômetros, o número do tensiômetro, o potencial matricial, a umidade com base em volume, a espessura de cada camada, a lâmina requerida e o valor do percentímetro.

Verificando a hora salva no arquivo, observa-se diferença de apenas alguns segundos entre a irrigação de um setor e outro; isso ocorreu porque o arquivo foi gerado em um teste de simulação feito em laboratório. Ainda não foi possível testar o sistema desenvolvido em campo. 


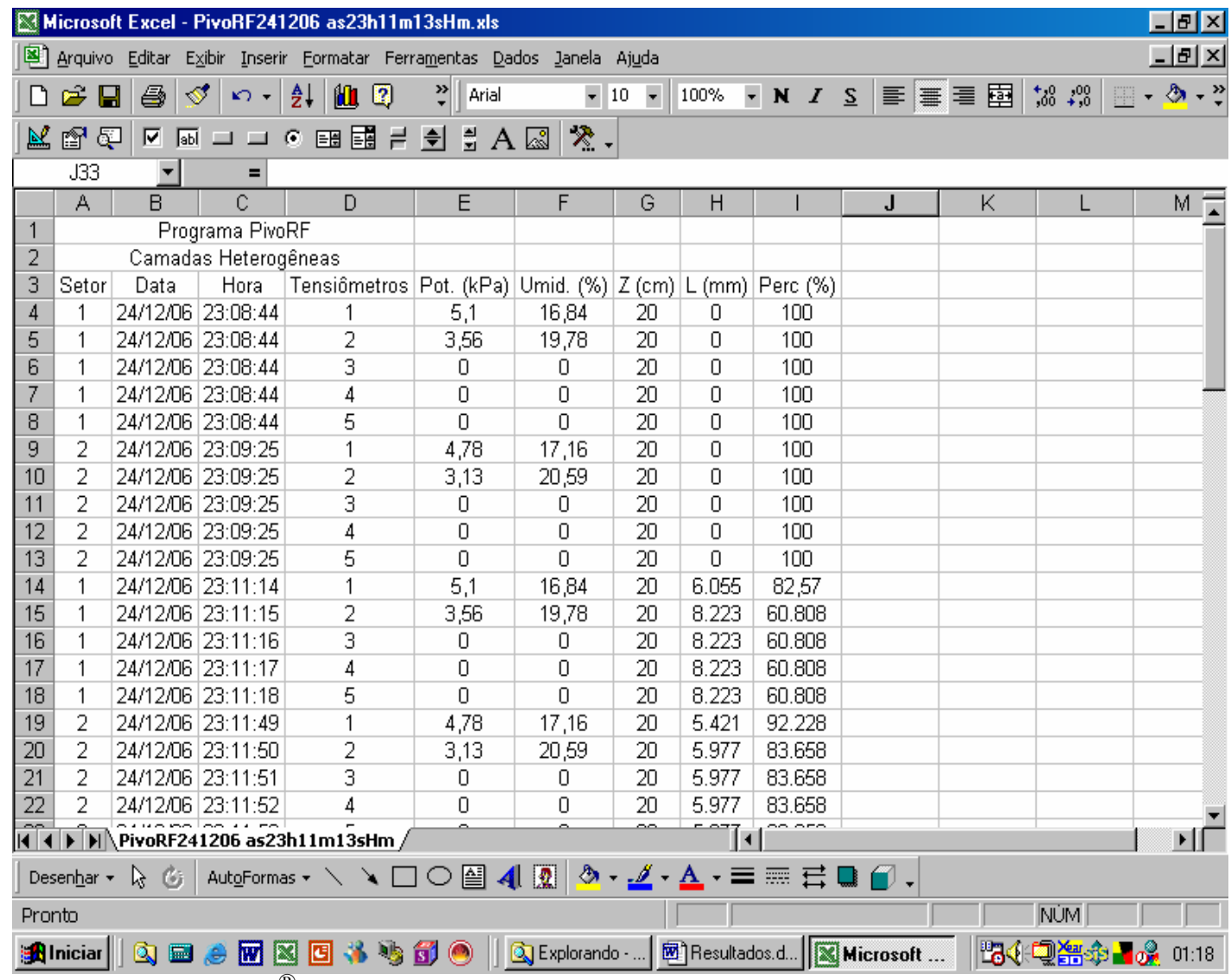

FIGURA 7. Tela do Excel ${ }^{\circledR}$ mostrando arquivo de dados gerados pelo PivoRFusuario. Excel screen showing a data file generated by PivoRFusuario.

Na Figura 8, são mostrados os circuitos de acionamento e de monitoramento, acondicionados em uma caixa própria para essa finalidade.

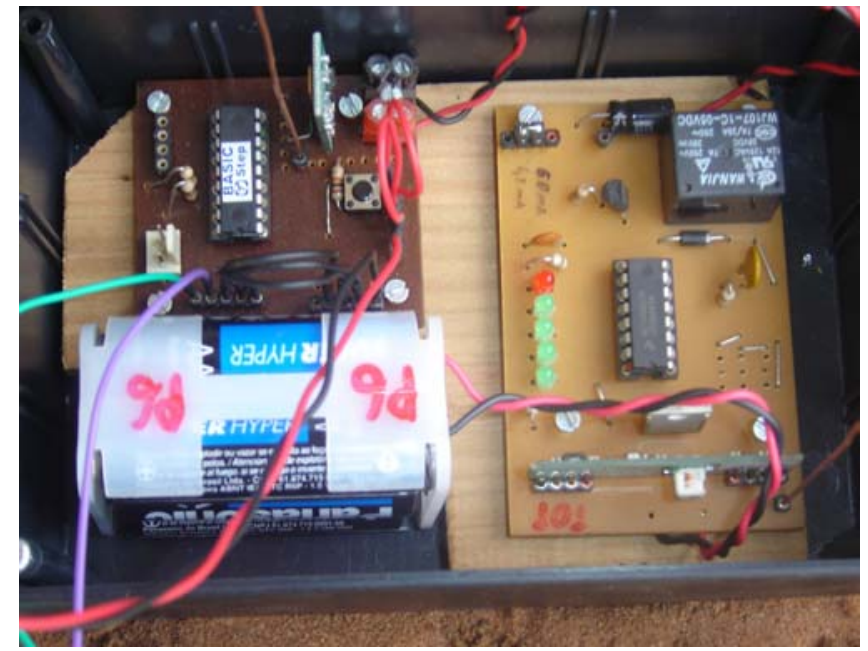

FIGURA 8. Caixa contendo os circuitos de acionamento (direita) e monitoramento (esquerda). Box containing the Trigger circuits (right) and tracking (left).

Observa-se que os circuitos são bastante simples, podendo ser facilmente construídos por qualquer pessoa com habilidade em eletrônica. Nota-se, no canto inferior esquerdo, o suporte de pilhas utilizado para a alimentação dos circuitos. Nesse, foram acondicionadas seis pilhas de 1,5 Vcc em série. Foram feitos, em laboratório, 1.500 testes para a averiguação do funcionamento, conseguindo êxito. Erros na transmissão do sinal de acionamento, por controle remoto, foram observados nas horas mais quentes do dia. Entretanto, como esse efeito não foi previsto, a temperatura não foi monitorada para confirmação de tal hipótese. Nos testes feitos para identificar a 
distância máxima de comunicação dos módulos de RF, constatou-se que, quando a distância entre transmissor e receptor foi maior do que $60 \mathrm{~m}$, a comunicação não foi eficiente, sendo necessário tempo muito elevado (5 minutos) para que o computador conseguisse identificar os valores dos 5 canais do A/D representativo da leitura dos tensiômetros. Quando a distância foi menor ou igual a $50 \mathrm{~m}$, o tempo médio de leitura dos 5 canais foi de 9,2 segundos, sem falhas.

Na Figura 9, é mostrada a placa de circuito impresso construída para a "interface" com o computador.

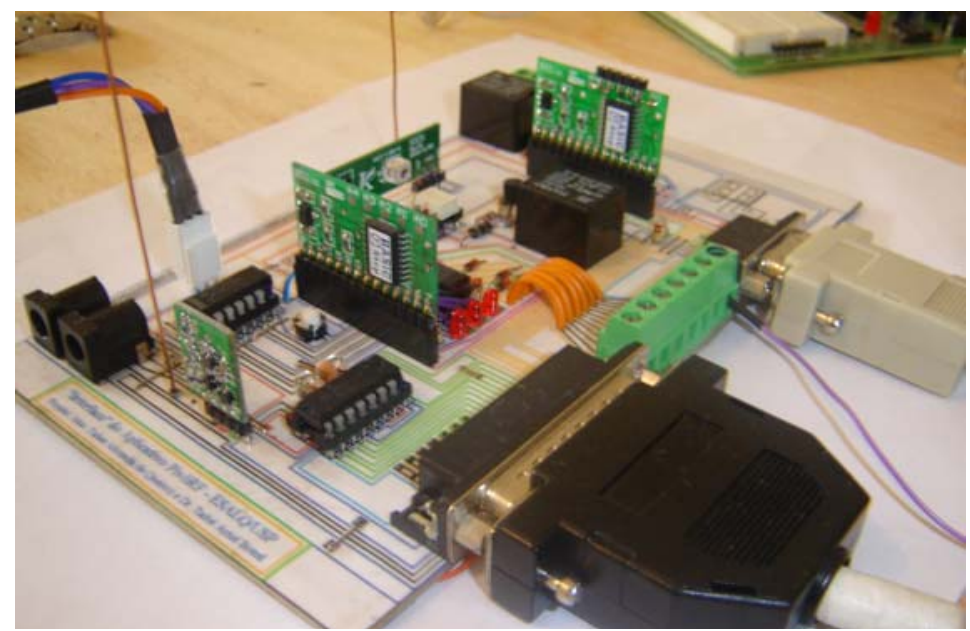

FIGURA 9. Placa de circuito impresso da "interface" PivoRF. Printed circuit card of the PivoRF interface.

Nos testes feitos, constatou-se que a "interface" PivoRF funcionou adequadamente, mostrando ser uma poderosa ferramenta para aquisição de dados via radiofreqüência.

\section{CONCLUSÕES}

Os resultados mostraram que tanto os softwares quanto os hardwares desenvolvidos apresentaram funcionamento satisfatório, indicando que o sistema tem potencial para aplicação prática, havendo a necessidade apenas de aumentar o alcance dos rádios.

\section{AGRADECIMENTOS}

Ao Prof. Dr. Miguel A. I. T. Del Pino, pelas preciosas dicas na programação Delphi, e ao Sr. Gustavo H. M. Arruda, pelas dicas na transmissão de dados via radiofreqüência.

\section{REFERÊNCIAS}

ANGELOTTI NETTO, A.; FERNANDES, E.J. Condutividade hidráulica de um Latossolo Vermelho em pousio e cultivo intensivo. Pesquisa Agropecuária Brasileira, Brasília, v.40, n.8, p797-802, 2005.

BERNARDO, S.; SOARES, A.A.; MANTOVANI, E.C. Manual de irrigação. 8. ed. Viçosa: UFV, 2006. 625 p.

MEDICI, L.O. Acionador automático de sistemas de irrigação. Revista da Propriedade Industrial, Rio de Janeiro, n.1399, 1997.

MESSIAS, A.R. LptWireless - Controlando 8 dispositivos via RF (RR3 e RT4). Disponível em: http://rogercom.com./pparalela/LptWireless.htm. Acesso em: 3 jun. 2005

QUEIROZ, T.M. Avaliação de sistema alternativo de automação da irrigação na cultura do Feijoeiro (Phaseolus vulgaris L.). 2004. 120f. Dissertação (Mestrado em Irrigação e Drenagem) Universidade Federal de Lavras, Lavras, 2004. 
QUEIROZ, T.M.; GIACOMIN, J.C.; RABELO, G.F.; BRAGA JÚNIOR, R.A. Circuito eletrônico para controle automático, em malha fechada, de sistemas de irrigação, através de tensiômetros. In: CONGRESSO BRASILEIRO DE ENGENHARIA AGRÍCOLA, 31., 2002, Salvador. Anais... Salvador: SBEA, 2002. 1 CD-ROM.

SAAD A.M.; LIBARDI P.L. Aferição do controle da irrigação feito pelos agricultores utilizando tensiômetros de faixas. In: ENCONTRO NACIONAL DE PRODUTORES IRRIGANTES, 5. 1994. São Paulo. Anais... São Paulo: IPT, 1992, p.27.

TEIXEIRA, A.S.; COELHO, S.L. Desenvolvimento e calibração de um tensiômetro eletrônico de leitura automática. Engenharia Agrícola, Jaboticabal, v.25, n.2, p.367-376, 2005.

VILELA, L.A.A. Metodologia para dimensionamento de um sistema de pulverização acoplável a pivô central. 2002. 127 f. Tese (Doutorado em Irrigação e Drenagem) - Escola Superior de Agricultura Luiz de Queiroz, Universidade de São Paulo, Piracicaba, 2002.

XAVIER, A.C.; COELHO, R.D.; LOURENÇO, L.F.; MACHADO, R.E. Manejo da irrigação em pastagem irrigada por pivô central. Revista Brasileira de Engenharia Agrícola e Ambiental, Campina Grande, v.8, n.2/3, p.233-9, 2004. 